\title{
Vegetação arbórea em remanescentes florestais urbanos: Bosque do Lago da Paz, Dois Vizinhos, PR
}

Flávia Gizele Konig Brun ${ }^{1}$, Eleandro José Brun ${ }^{1 *}$, Solon Jonas Longhi , Maurício Romero Gorenstein ${ }^{1}$, Tamara Ribeiro Botelho Carvalho Maria ${ }^{2}$, Géssica Mylena Santana Rêgo ${ }^{3}$, Tathiana Tominaga Higa ${ }^{1}$

1 Universidade Tecnológica Federal do Paraná, Entrada para Boa Esperança, Km 4, CP. 157, CEP 85660-000, Dois Vizinhos, PR, Brasil

${ }^{2}$ Universidade Federal do Paraná, Av. Pref. Lothário Meissner, 632, Jardim Botânico, CEP 80210-170, Curitiba, PR, Brasil

${ }^{3}$ Universidade Estadual do Norte Fluminense, Av. Alberto Lamego, 2000, Horto, CEP 28013-602, Campos dos Goytacazes, RJ, Brasil

"Autor correspondente:

eleandrobrun.utfpr@gmail.com

Termos para indexação:

Conservação

Espécies exóticas

Espécies invasoras

Index terms:

Forestry conservation

Exotic species

Invasive species

Histórico do artigo:

Recebido em 12/02/2017

Aprovado em 05/12/2017

Publicado em 29/12/2017

doi: 10.4336/2017.pfb.37.92.1405
Resumo - Esse estudo teve por objetivo analisar a florística, estrutura e diversidade da vegetação arbórea e da regeneração de um fragmento florestal situado na área urbana de Dois Vizinhos, PR, por meio do método de censo. Foram utilizados os descritores fitossociológicos tradicionais como parâmetros de análise, dando indicações sobre o valor ecológico do fragmento. Evidenciou-se a ocorrência de 231 indivíduos em 2.500 $\mathrm{m}^{2}$ de área, distribuídos em 35 espécies de 22 famílias botânicas. As famílias com maior número de espécies foram Lauraceae e Myrtaceae, com três espécies cada, seguida por Boraginaceae, Euphorbiaceae, Fabaceae, Meliaceae, Myrsinaceae, Rosaceae e Sapindaceae, com duas espécies cada, ficando as demais famílias com uma espécie cada. Entre as oito espécies exóticas, quatro são invasoras potenciais, tais como Ligustrum lucidum (34,04\%) e Dyospyrus kaki (13,59\%), destacando-se pelo alto valor de cobertura (VC) e pela dominância, com mais de $50 \%$ dos indivíduos. A maioria das espécies encontradas pertence a estágios iniciais de sucessão. Na regeneração, foram encontradas 20 espécies, com apenas três exóticas e, dentre estas, uma invasora (L. lucidum). A ocorrência de espécies exóticas invasoras em fragmentos florestais urbanos demanda a atenção dos gestores públicos quanto à necessidade de intervenções silviculturais, visando à recuperação da florística e estrutura original.

\section{Tree vegetation in an urban remnant: Lago da Paz forest, Dois Vizinhos, PR, Brazil}

\begin{abstract}
This study had the objective to analyze the floristic, structure and diversity of regeneration of a forest fragment located in the urban area of Dois Vizinhos, Paraná State. We used the census method and the traditional phytosociological descriptors as parameters of analysis, giving indications about the ecological value of the fragment. The results showed the occurrence of 231 individuals in $2,500 \mathrm{~m}^{2}$ area, distributed in 35 species of 22 botanical families. The families with the highest number of species were Lauraceae and Myrtaceae, with three species each, followed by Boraginaceae, Euphorbiaceae, Fabaceae, Meliaceae, Myrsinaceae, Rosaceae and Sapindaceae with two species each. The others were represented by one species each. Among eight exotic species, four are potential invaders, such as Ligustrum lucidum (34.0\%) and Dyospyrus kaki $(13.6 \%)$ that presented high coverage value (CV) and dominance with more than $50 \%$ of the registered individuals. Most of the species belong to the initial stages of succession. In the regeneration, we found 20 species, with only tree exotics and, among them, only one invasive (L. lucidum). The occurrence of exotic invasive species in urban forest fragments requires attention of public managers to the necessity of silvicultural interventions to recover their floristic and original structure.
\end{abstract}




\section{Introdução}

As florestas urbanas podem ser definidas como redes ou sistemas que compreendem todas as florestas, grupos de árvores e árvores individuais localizadas em áreas urbanas e periurbanas. Incluem, portanto, florestas, árvores de rua, árvores em parques e jardins e árvores em locais abandonados. Essas são a espinha dorsal da infraestrutura verde de uma cidade, pois podem melhorar o conforto ambiental (Salbitano et al., 2016).

O termo floresta urbana foi primeiramente utilizado nos Estados Unidos em 1894, mas o conceito sofreu mudanças na década de 1960, com uma abordagem abrangente e interdisciplinar para os desafios específicos relacionados ao cultivo de árvores em ambientes urbanos. Assim, as florestas urbanas podem ser definidas como todas as árvores individuais e as áreas de florestas no perímetro urbano e entorno das cidades. Pode-se utilizar a terminologia silvicultura urbana, definindo como a arte, ciência e tecnologia de manejo de árvores e recursos florestais em e ao redor dos ecossistemas comunitários urbanos, para os benefícios fisiológicos, sociológicos, econômicos e estéticos que proporcionam à sociedade (Konijnendijka et al., 2006).

Entre alguns destes benefícios, Nowak et al. (2007) mencionam a remoção da poluição do ar, redução das temperaturas e dos raios ultravioletas, melhoria da qualidade da água, armazenamento e sequestro do carbono, redução do uso de energia elétrica dos edifícios e aumento da vida selvagem. Citam também os benefícios sociais, como saúde, recreação e lazer, e econômicos relacionados à mitigação de prejuízos causados por tempestades. A floresta urbana, na realidade, pode atender aos requisitos mencionados por Constanza et al. (1997) como serviços ecossistêmicos.

Badiru et al. (2005) destacam também que as florestas urbanas representam um referencial urbanístico de forte cunho social, político, econômico e paisagístico, servindo diariamente à comunidade o contato com a natureza, ao realizarem suas atividades rotineiras.

Além disso, a vegetação urbana fornece uma série de benefícios, dentre eles: conforto climático; absorção de $\mathrm{CO}_{2}$ do ar; proteção dos mananciais, redução do impacto das chuvas, entre outros (Rezende \& Santos, 2010).

Embora apresentem enormes benefícios, os fragmentos florestais urbanos estão sujeitos a impactos antrópicos frequentes e tendem a apresentar estrutura tipicamente secundária, com fortes impedimentos para a progressão da sucessão florestal, causando diminuição da biodiversidade em nível regional (McKinney, 2008).

A fragmentação das florestas urbanas, dentre outros motivos socioeconômicos, ocorreu em função do êxodo rural e estabelecimento de moradias urbanas de forma desordenada. A utilização dos recursos naturais pelo homem, sem o devido planejamento, também tem provocado impactos a estas florestas, reduzindo-as e comprometendo a manutenção e sustentabilidade da biodiversidade. Assim, evidencia-se a importância do conhecimento da florística e da dinâmica das comunidades ainda existentes nos centros urbanos e a conservação dos remanescentes florestais (Salles \& Schiavini, 2007).

Nowak et al. (2007) comentam sobre a importância da manutenção da composição e da diversidade de espécies no fornecimento para as populações dos vários serviços ecossistêmicos das florestas urbanas. Relatam que a composição e a diversidade de espécies estão mudando em todo o mundo e continuarão a mudar no futuro, estando sob ameaça de várias forças. Informam que há necessidade de estudos e planos de manejo das florestas urbanas existentes, visando sustentá-las saudáveis e funcionais para as gerações futuras.

Bianchini et al. (2003) e Schorn et al. (2014) descrevem a importância dos estudos florísticos e fitossociológicos, que permitem avaliar o estado atual dos fragmentos analisados, além de fornecer subsídios para possíveis estratégias de recuperação, principalmente de áreas de vegetação urbanas, que sofrem permanentes pressões antrópicas.

A Floresta Ombrófila Mista foi extremamente alterada durante o processo de ocupação. Restam somente 3\% de remanescentes e apenas $0,8 \%$ mais conservados no estado do Paraná (Kersten et al., 2015). Em Dois Vizinhos, os dados são ainda mais preocupantes, restando somente 389 ha de florestas em estágio avançado, o que corresponde a somente $0,93 \%$ da área de florestas naturais do município (Hirota, 2011).

Áreas de florestas secundárias necessitam de intervenção, a fim de assegurar a conservação de sua biodiversidade. Atualmente, essas florestas apresentam, de forma geral, uma simplificação florística, com espécies generalistas, além de espécies exóticas invasoras (Kersten et al., 2015).

Projetos de extensão florestal, visando à educação ambiental, são fundamentais na conscientização da população sobre a importância de se conservar as florestas 
de pinheiro-do-paraná e espécies a ele associadas, tais como Ocotea porosa (imbuia), Balfourodendron riedelianum (pau-marfim), Aspidosperma polyneuron (peroba-rosa), Cedrela fissilis (cedro), Apuleia leiocarpa (grápia), Ilex paraguariensis (erva-mate), além de outras espécies, como Maytenus ilicifolia (espinheira santa) e também espécies de Lauraceae, Myrtaceae ou mesmo Disksonia sellowiana (xaxim ou samambaiaçu), Podocarpus lambertii (pinheiro-bravo), entre tantas outras.

Enriquecer as florestas nativas com espécies nativas de valor madeireiro e ecológico é o desafio que o setor florestal tem hoje, e que vem sendo feito em outros estados de forma mais intensiva, como em São Paulo, onde ocorrem diversos programas de recomposição de florestas nativas (Iniciativa Verde, 2017). Essas práticas, em larga escala, podem contribuir para a redução dos riscos de extinção das espécies nativas ameaçadas e para ampliar a oferta de serviços ecossistêmicos à sociedade.

Assim, o presente trabalho foi realizado com o objetivo de analisar a vegetação do fragmento florestal da Praça do Lago da Paz, em Dois Vizinhos, PR, a fim de identificar as condições ambientais do fragmento, tornando este estudo uma base de replicação e de tomada de decisão para gestores públicos preocupados com a conservação de suas florestas urbanas.

\section{Material e métodos}

O estudo foi realizado em um fragmento florestal urbano denominado "Bosque da Praça do Lago da Paz", com área de aproximadamente $2.500 \mathrm{~m}^{2}$, localizado na cidade de Dois Vizinhos, sudoeste do Estado do Paraná. O município está localizado no terceiro planalto paranaense, com altitude média de $520 \mathrm{~m}$, nas coordenadas centrais de $25^{\circ} 74^{\prime} \mathrm{S}$ e $53^{\circ} 06^{\prime} \mathrm{W}$.

Conforme a classificação de Alvares et al. (2013), a região apresenta o tipo climático $\mathrm{Cfa}$, pluvial temperado úmido, com a temperatura do mês mais frio entre $18^{\circ} \mathrm{Ce}-3{ }^{\circ} \mathrm{C}$ e temperatura do mês mais quente acima de $22{ }^{\circ} \mathrm{C}$. A precipitação média anual fica entre 1.800-2.000 mm, bem distribuída durante o ano. O solo predominante no município é do tipo Latossolo Vermelho Distroférrico típico, de textura argilosa (Santos et al., 2013).

A floresta urbana estudada compõe a mata ciliar do lago da Paz, situada no interior da área urbana do município. Tal fragmento será alvo de plano de manejo de restauração para plantio de espécies arbóreas típicas da Floresta Ombrófila Mista, visando práticas de educação ambiental para a comunidade. Além do bosque e do lago, a área conta com outras estruturas, como um pequeno campo de futebol de areia, pracinha de brinquedos, edificação, utilizada como sede da Associação de Proteção à Maternidade e Infância (APMI), pista de caminhada no entorno do lago e academia ao ar livre. Fora da área da Praça do Lago da Paz, junto à área de preservação permanente do curso d'água que se forma como vertedouro do lago, existem construções irregulares, com evidências de impactos ambientais daí decorrentes, tais como resíduos sólidos e esgoto despejado no curso d'água.

$\mathrm{O}$ fragmento florestal estudado apresenta regeneração contínua, na maior parte da área, indicando que as práticas de roçadas visando à limpeza da vegetação são restritas às áreas mais próximas à pista de caminhada que atravessa o fragmento. A regeneração foi amostrada através de três transectos, em duas classes de tamanho, tendo como referência a altura e o diâmetro a $1,30 \mathrm{~m}$ do solo (DAP): varas: $1 \mathrm{~cm}<\mathrm{DAP}<8 \mathrm{~cm}$ e mudas: altura de $0,1 \mathrm{~m}$ até $1 \mathrm{~cm}$ de DAP.

O levantamento da vegetação arbórea foi realizado por meio de censo, sendo analisados todos os indivíduos arbóreos com DAP $\geq 8 \mathrm{~cm}$. Cada indivíduo foi identificado ao nível de espécie, sendo medido o DAP com fita métrica $(\mathrm{cm})$. Os indivíduos que não foram identificados in loco, tiveram material botânico coletado, sendo as exsicatas levadas ao Herbário do Curso de Engenharia Florestal da UTFPR Campus Dois Vizinhos, para identificação.

Após medição e identificação dos indivíduos, os dados foram tabulados em planilha eletrônica e posteriormente calculados os índices fitosssociológicos: número de indivíduos $(\mathrm{Ni})$, área basal $(\mathrm{G})$, densidade absoluta (DA), densidade relativa (DR), dominância absoluta (DoA), dominância relativa (DoR) e valor de cobertura (VC), visando avaliar a florística e estrutura atual do fragmento urbano. Também foram calculados os índices de diversidade de Shannon e de Equabilidade de Pielou, conforme utilizado por Felfili et al. (2011). Para efeito de comparação, Mueller-Dombois \& Ellenberg (2002) e Magurran (2013), entre outros pesquisadores em fitossociologia, consideram que o índice de diversidade de Shannon pode variar de 1 a 3,5, podendo atingir até 4,5 . 
A classificação das espécies em grupos ecológicos de sucessão foi feita baseando-se em observações de campo e revisão de literatura, considerando, principalmente, as seguintes obras: Klein (1972), Reitz et al. (1988), Tabarelli (1992), Scipione et al. (2013), Silva et al. (2010), assim como na metodologia de Swaine \& Whitmore (1988), que classifica os estágios de sucessão em pioneiras e clímax, estas últimas classificadas em exigentes em luz e tolerantes à sombra.

\section{Resultados}

No fragmento florestal urbano avaliado foram encontrados 231 indivíduos arbóreos, pertencentes a 35 espécies de 22 famílias botânicas e uma não identificada, envolvendo espécies nativas e exóticas. As famílias com maior número de espécies foram Fabaceae, Lauraceae, Myrtaceae e Sapindaceae (18,2\%), com três espécies cada, seguidas por Euphorbiaceae, Meliaceae, Primulaceae, Rosaceae e Rutaceae (22,7\%) com duas espécies. As demais famílias $(59,1 \%)$ foram representadas por uma única espécie cada (Tabela 1).

Entre as espécies encontradas, 27 são nativas $(77,1 \%)$ e oito exóticas (22,9\%). Destas espécies, 31,4\% são pioneiras, 54,3\% são clímax exigentes em luz e 14,3\% são clímax tolerantes à sombra (Tabela 1).

As espécies com maior número de indivíduos foram Ligustrum lucidum (65), Diospyrus kaki (28), Parapiptadenia rigida (13), Hovenia dulcis (12) e Eugenia uniflora (10), representando aproximadamente $55 \%$ dos indivíduos encontrados. Destas cinco espécies, três são exóticas (L. lucidum, H. dulcis e Pinus sp.) e consideradas invasoras, conforme a Lista de Espécies Exóticas Invasoras do Estado do Paraná (Instituto Ambiental do Paraná, 2015). Do total dos indivíduos encontrados no fragmento, 53,68\% são de espécies exóticas e $46,32 \%$ de espécies nativas.

Em nível geral, observa-se que as espécies arbóreas formam um estrato contínuo e único, com certa variação nas alturas, havendo somente uma separação em relação à regeneração natural, formado por varas e mudas, que compõem um estrato inferior.

Os resultados do estudo da regeneração ocorrente na área estão apresentados na tabela 2 . Foram encontrados
103 indivíduos considerados como mudas, abrangendo plantas maiores que $10 \mathrm{~cm}$ de altura até $1 \mathrm{~cm}$ de diâmetro à $1,30 \mathrm{~m}$ de altura (DAP). Nota-se que o camboatábranco apresentou 79 indivíduos, sendo a maioria proveniente de brotos de raízes expostas sobre o solo, em função da erosão hídrica e do trânsito de pessoas na área. Em segundo lugar, a guavirova apresentou sete indivíduos, seguida do coqueiro jerivá, com três, aspectos importantes uma vez que são espécies de grande relevância como fonte alimentar para a avifauna.

Quanto à categoria varas, abrangendo plantas com 1 $\mathrm{cm}<\mathrm{DAP} \leq 8 \mathrm{~cm}$, foram encontrados 16 indivíduos, com destaque para o ligustro, com sete indivíduos, mostrando que a invasão biológica é significativa na área, devido à existência de indivíduos tanto adultos como na regeneração.

Em relação à dominância, destacou-se Pinus sp., com um número não muito expressivo de indivíduos, porém sendo os mesmos de grandes dimensões, alcançando $7,69 \mathrm{~m}^{2}$ ha $^{-1}$, o que perfez $26,2 \%$ da dominância. $L$. lucidum, pelo maior número de indivíduos, foi a segunda espécie em dominância $\left(6,64 \mathrm{~m}^{2} \mathrm{ha}^{-1}\right.$, representando $22,7 \%$ do total, seguido da H. dulcis $\left(2,18 \mathrm{~m}^{2} \mathrm{ha}^{-1}\right.$ representando 7,4\%).

Pode-se observar, também, que as espécies mais características e predominantes do remanescente urbano estudado foram L. lucidum, Pinus sp., D. kaki, H. dulcis, P. rigida, Araucaria angustifolia e E. uniflora, que em conjunto representam aproximadamente $66 \%$ do valor de cobertura (VC) total. Destacou-se, entre elas, o ligustro, com $25,4 \%$ de VC. Dentre estas principais espécies, as quatro primeiras são exóticas e representam $53,6 \%$ de VC. Ocorreram, também, outras quatro espécies exóticas (Eucalyptus sp., Eriobotrya japonica, Citrus aurantium subsp. bergamia, Citrus x aurantium), que representam $5,4 \%$ do VC. Estas oito espécies exóticas, em conjunto, representam $59 \%$ do VC, indicando alto grau de invasão biológica na estrutura do fragmento urbano.

O índice de diversidade de Shannon (H') calculado foi de 2,88, indicando que o fragmento urbano apresenta média diversidade. No entanto, o índice de Equabilidade de Pielou $(0,804)$ indicou que poucas espécies estão dominando a área. 
Tabela 1. Índices fitossociológicos das espécies ocorrentes no fragmento florestal da Praça do Lago da Paz em Dois Vizinhos, PR.

\begin{tabular}{|c|c|c|c|c|c|c|c|c|c|}
\hline Nome científico & OR & GE & NI & DA & DR\% & DoA & DoR\% & VC & VC\% \\
\hline \multicolumn{10}{|l|}{ ANACARDIACEAE } \\
\hline Schinus terebinthifolia Raddi & $\mathrm{N}$ & $P$ & 2 & 8,03 & 0,9 & 0,12 & 0,4 & 1,29 & 0,6 \\
\hline \multicolumn{10}{|l|}{ ANNONACEAE } \\
\hline Annona sylvatica A.St.-Hil. & $\mathrm{N}$ & $\mathrm{CS}$ & 3 & 12,05 & 1,3 & 0,16 & 0,6 & 1,84 & 0,9 \\
\hline \multicolumn{10}{|l|}{ AQUIFOLIACEAE } \\
\hline Ilex microdonta Reissek & $\mathrm{N}$ & $\mathrm{CL}$ & 2 & 8,03 & 0,9 & 0,53 & 1,8 & 2,68 & 1,3 \\
\hline \multicolumn{10}{|l|}{ ARALIACEAE } \\
\hline $\begin{array}{c}\text { Schefflera morototoni (Aubl.) Maguire } \\
\text { et al. }\end{array}$ & $\mathrm{N}$ & $\mathrm{CS}$ & 1 & 4,02 & 0,4 & 0,18 & 0,6 & 1,05 & 0,5 \\
\hline \multicolumn{10}{|l|}{ ARAUCARIACEAE } \\
\hline Araucaria angustifolia (Bertol.) Kuntze & $\mathrm{N}$ & $P$ & 6 & 24,10 & 2,6 & 1,94 & 6,6 & 9,21 & 4,6 \\
\hline \multicolumn{10}{|l|}{ ARECACEAE } \\
\hline Syagrus romanzoffiana (Cham.) Glassman & $\mathrm{N}$ & CL & 2 & 8,03 & 0,9 & 0,28 & 0,9 & 1,81 & 0,9 \\
\hline \multicolumn{10}{|l|}{ BORAGINACEAE } \\
\hline $\begin{array}{c}\text { Cordia americana (L.) Gottschling \& } \\
\text { J.S.Mill. }\end{array}$ & $\mathrm{N}$ & $\mathrm{CL}$ & 4 & 16,06 & 1,7 & 0,46 & 1,6 & 3,29 & 1,6 \\
\hline \multicolumn{10}{|l|}{ EBENACEAE } \\
\hline Diospyros kaki Thunb. & $\mathrm{E}$ & $\mathrm{P}$ & 28 & 112,45 & 12,1 & 0,72 & 2,4 & 14,56 & 7,3 \\
\hline \multicolumn{10}{|l|}{ EUPHORBIACEAE } \\
\hline Alchornea sidifolia Müll.Arg. & $\mathrm{N}$ & $\mathrm{CL}$ & 2 & 8,03 & 0,9 & 0,49 & 1,7 & 2,55 & 1,3 \\
\hline Gymnanthes klotzschiana Müll.Arg. & $\mathrm{N}$ & $\mathrm{CL}$ & 3 & 12,05 & 1,3 & 0,34 & 1,2 & 2,46 & 1,2 \\
\hline \multicolumn{10}{|l|}{ FABACEAE } \\
\hline Bauhinia forficata Link & $\mathrm{N}$ & $P$ & 3 & 12,05 & 1,3 & 0,06 & 0,2 & 1,51 & 0,8 \\
\hline Dalbergia frutescens (Vell.) Britton & $\mathrm{N}$ & CL & 5 & 20,08 & 2,2 & 0,35 & 1,2 & 3,37 & 1,7 \\
\hline Parapiptadenia rigida (Benth.) Brenan & $\mathrm{N}$ & $\mathrm{CL}$ & 13 & 52,21 & 5,6 & 1,33 & 4,5 & 10,16 & 5,1 \\
\hline \multicolumn{10}{|l|}{ LAURACEAE } \\
\hline Nectandra lanceolata Nees & $\mathrm{N}$ & CS & 2 & 8,03 & 0,9 & 0,23 & 0,8 & 1,64 & 0,8 \\
\hline Nectandra megapotamica (Spreng.) Mez & $\mathrm{N}$ & $\mathrm{CS}$ & 3 & 12,05 & 1,3 & 0,27 & 0,9 & 2,23 & 1,1 \\
\hline Ocotea puberula (Rich.) Nees & $\mathrm{N}$ & $\mathrm{CL}$ & 3 & 12,05 & 1,3 & 0,16 & 0,6 & 1,84 & 0,9 \\
\hline \multicolumn{10}{|l|}{ MALVACEAE } \\
\hline Ceiba speciosa (A.St.-Hil.) Ravenna & $\mathrm{N}$ & $\mathrm{CL}$ & 1 & 4,02 & 0,4 & 0,41 & 1,4 & 1,83 & 0,9 \\
\hline \multicolumn{10}{|l|}{ MELIACEAE } \\
\hline Cabralea canjerana (Vell.) Mart. & $\mathrm{N}$ & $\mathrm{CS}$ & 2 & 8,03 & 0,9 & 0,28 & 0,9 & 1,81 & 0,9 \\
\hline Cedrela fissilis Vell. & $\mathrm{N}$ & CL & 1 & 4,02 & 0,4 & 0,10 & 0,4 & 0,78 & 0,4 \\
\hline \multicolumn{10}{|l|}{ MYRTACEAE } \\
\hline $\begin{array}{c}\text { Campomanesia xanthocarpa (Mart.) } \\
\text { O.Berg }\end{array}$ & $\mathrm{N}$ & $\mathrm{CL}$ & 6 & 24,10 & 2,6 & 0,32 & 1,1 & 3,69 & 1,8 \\
\hline Eugenia uniflora L. & $\mathrm{N}$ & $\mathrm{CL}$ & 10 & 40,16 & 4,3 & 0,45 & 1,6 & 5,88 & 2,9 \\
\hline Eucalyptus sp. & $\mathrm{E}$ & $\mathrm{CL}$ & 2 & 8,03 & 0,9 & 1,11 & 3,8 & 4,66 & 2,3 \\
\hline \multicolumn{10}{|l|}{ OLEACEAE } \\
\hline Ligustrum lucidum W.T.Aiton & $\mathrm{E}$ & $\mathrm{P}$ & 65 & 261,04 & 28,1 & 6,64 & 22,7 & 50,80 & 25,4 \\
\hline \multicolumn{10}{|l|}{ PINACEAE } \\
\hline Pinus sp. & $\mathrm{E}$ & $\mathrm{P}$ & 7 & 28,11 & 3,0 & 7,69 & 26,2 & 29,25 & 14,6 \\
\hline
\end{tabular}


Tabela 1. continuação.

\begin{tabular}{|c|c|c|c|c|c|c|c|c|c|}
\hline Nome científico & OR & GE & NI & DA & DR\% & DoA & DoR\% & $\mathrm{VC}$ & $\mathrm{VC} \%$ \\
\hline \multicolumn{10}{|l|}{ PRIMULACEAE } \\
\hline Myrsine loefgrenii (Mez) Imkhan. & $\mathrm{N}$ & $\mathrm{CL}$ & 3 & 12,05 & 1,3 & 0,11 & 0,4 & 1,69 & 0,8 \\
\hline Myrsine umbellata Mart. & $\mathrm{N}$ & CL & 3 & 12,05 & 1,3 & 0,14 & 0,5 & 1,76 & $\mathrm{O}, 9$ \\
\hline \multicolumn{10}{|l|}{ RHAMNACEAE } \\
\hline Hovenia dulcis Thunb. & $\mathrm{E}$ & $\mathrm{P}$ & 12 & 48,19 & 5,2 & 2,18 & 7,4 & 12,63 & 6,3 \\
\hline \multicolumn{10}{|l|}{ ROSACEAE } \\
\hline Eriobotrya japonica (Thunb.) Lindl. & $\mathrm{E}$ & $P$ & 7 & 28,11 & 3,0 & 0,11 & 0,4 & 3,40 & 1,7 \\
\hline Prunus myrtifolia (L.) Urb. & $\mathrm{N}$ & $\mathrm{CL}$ & 8 & 32,13 & 3,5 & 0,31 & 1,0 & 4,50 & 2,3 \\
\hline \multicolumn{10}{|l|}{ RUTACEAE } \\
\hline $\begin{array}{c}\text { Citrus aurantium subsp. bergamia (Risso) } \\
\text { Wight \& Arn. }\end{array}$ & $\mathrm{E}$ & $\mathrm{P}$ & 2 & 8,03 & 0,9 & 0,33 & 1,1 & 2,00 & 1,0 \\
\hline Citrus $\mathrm{x}$ aurantium $\mathrm{L}$. & $\mathrm{E}$ & $\mathrm{P}$ & 1 & 4,02 & 0,4 & 0,08 & 0,3 & 0,71 & 0,4 \\
\hline \multicolumn{10}{|l|}{ SALICACEAE } \\
\hline Casearia sylvestris $\mathrm{Sw}$. & $\mathrm{N}$ & $\mathrm{P}$ & 5 & 20,08 & 2,2 & 0,31 & 1,1 & 3,22 & 1,6 \\
\hline \multicolumn{10}{|l|}{ SAPINDACEAE } \\
\hline $\begin{array}{l}\text { Allophylus edulis (A.St.-Hil. et al.) } \\
\text { Hieron. ex Niederl. }\end{array}$ & $\mathrm{N}$ & $\mathrm{CL}$ & 5 & 20,08 & 2,2 & 0,23 & 0,8 & 2,94 & 1,5 \\
\hline Cupania vernalis Cambess. & $\mathrm{N}$ & $\mathrm{CL}$ & 3 & 12,05 & 1,3 & 0,42 & 1,4 & 2,72 & 1,4 \\
\hline Matayba elaeagnoides Radlk. & $\mathrm{N}$ & $\mathrm{CL}$ & 5 & 20,08 & 2,2 & 0,46 & 1,6 & 3,72 & 1,9 \\
\hline Não identificada & & & 1 & 4,02 & 0,4 & 0,02 & 0,1 & 0,50 & 0,3 \\
\hline TOTAL & & & 231 & 927,7 & 100 & 29,3 & 100 & 200 & 100 \\
\hline
\end{tabular}

Onde: $\mathrm{OR}=$ origem: (N: nativa, E: exótica); $\mathrm{GE}=$ grupo ecológico (P: pioneira, CL: clímax exigentes em luz, CS: clímax tolerantes à sombra); $\mathrm{NI}=$ número de indivíduos amostrados; $\mathrm{DA}=$ densidade absoluta $\left(\mathrm{n}^{\mathrm{o}}\right.$ ind.ha $\left.{ }^{-1}\right) ; \mathrm{DR}=$ densidade relativa $(\%) ; \mathrm{G}=$ área basal amostrada $\left(\mathrm{m}^{2}\right) ; \mathrm{DoA}=$ dominância absoluta $\left(\mathrm{m}^{2} \cdot \mathrm{ha}^{-1}\right) ; \mathrm{DoR}=$ dominância relativa $(\%) ; \mathrm{VC}=$ valor de cobertura; $\mathrm{VC} \%=$ valor de cobertura em $\%$.

Tabela 2. Espécies e número de plantas regenerantes no fragmento florestal da Praça do Lago da Paz em Dois Vizinhos, PR.

\begin{tabular}{|c|c|c|c|c|}
\hline Família / Nome científico & Nome popular & Origem & Muda & Vara \\
\hline \multicolumn{5}{|l|}{ ANNONACEAE } \\
\hline Rollinia sylvatica (A. St.-Hil.) Mart. & Ariticum & $\mathrm{N}$ & 2 & 1 \\
\hline \multicolumn{5}{|l|}{ AQUIFOLIACEAE } \\
\hline Ilex microdonta Reissek & Caúna & $\mathrm{N}$ & 0 & 1 \\
\hline \multicolumn{5}{|l|}{ ARECACEAE } \\
\hline Syagrus romanzoffiana (Cham.) Glassman & Coqueiro & $\mathrm{N}$ & 3 & 0 \\
\hline \multicolumn{5}{|l|}{ BORAGINANEAE } \\
\hline Cordia americana (L.) Gottschling \& J. J. Mill. & Guajuvira & $\mathrm{N}$ & 0 & 1 \\
\hline \multicolumn{5}{|l|}{ CANNABACEAE } \\
\hline Celtis iguanaea (Jacq.) Sarg. & Esporão-de-galo & $\mathrm{N}$ & 1 & 0 \\
\hline \multicolumn{5}{|l|}{ EUPHORBIACEAE } \\
\hline Sebastiania commersoniana (Baill.) L. B. Sm. \& Downs & Branquilho & $\mathrm{N}$ & 0 & 1 \\
\hline \multicolumn{5}{|l|}{ FABACEAE } \\
\hline Parapiptadenia rigida (Benth.) Brenan & Angico-vermelho & $\mathrm{N}$ & 2 & 0 \\
\hline Pelthophorum dubium (Spreng) Taub. & Canafistula & $\mathrm{N}$ & 1 & 0 \\
\hline
\end{tabular}

Continua...

Pesq. flor. bras., Colombo, v. 37, n. 92, p. 503-512, out./dez. 2017 
Tabela 2. continuação.

\begin{tabular}{|c|c|c|c|c|}
\hline Família / Nome científico & Nome popular & Origem & Muda & Vara \\
\hline \multicolumn{5}{|l|}{ LAURACEAE } \\
\hline Cinnamomum zeylanicum Blume & Canela & $\mathrm{E}$ & 1 & 0 \\
\hline Ocotea puberula (Rich.) Nees. & Canela-preta & $\mathrm{N}$ & 1 & 0 \\
\hline \multicolumn{5}{|l|}{ MELIACEAE } \\
\hline Cedrela fissilis Vell. & Cedro & $\mathrm{N}$ & 1 & 0 \\
\hline \multicolumn{5}{|l|}{ MYRTACEAE } \\
\hline Campomanesia xanthocarpa (Mart.) O. Berg & Guavirova & $\mathrm{N}$ & 7 & 0 \\
\hline Psidium cattleianum Sabine & Araça-vermelho & $\mathrm{N}$ & 0 & 1 \\
\hline Eugenia uniflora $\mathrm{L}$. & Pitangueira & $\mathrm{N}$ & 1 & 1 \\
\hline Calyptranthes concinna DC. & Guamirim & $\mathrm{N}$ & 0 & 1 \\
\hline Myrciaria tenella (DC.) O. Berg & Cambuim & $\mathrm{N}$ & 1 & 0 \\
\hline \multicolumn{5}{|l|}{ OLEACEAE } \\
\hline Ligustrum lucidum W. T. Aiton & Ligustro & $\mathrm{E}$ & 0 & 7 \\
\hline \multicolumn{5}{|l|}{ ROSACEAE } \\
\hline Eriobotrya japonica (Thunb.) Lind. & Ameixeira-amarela & $\mathrm{E}$ & 1 & 1 \\
\hline \multicolumn{5}{|l|}{ SAPINDACEAE } \\
\hline Allophylus edulis (A.St.-Hil. et al.) Hieron. ex Niederl. & Chal-chal & $\mathrm{N}$ & 2 & 1 \\
\hline Matayba elaeagnoides Radlk. & Camboatá-branco & $\mathrm{N}$ & 79 & 0 \\
\hline Total & 20 espécies & - & 103 & 16 \\
\hline
\end{tabular}

Onde: $\mathrm{N}=$ nativa; $\mathrm{E}=$ exótica.

\section{Discussão}

Das 35 espécies encontradas no fragmento urbano estudado, oito são exóticas, das quais, segundo Instituto Ambiental do Paraná (IAP) (2015), quatro são invasoras potenciais (Eriobotrya japonica, Hovenia dulcis, Ligustrum lucidum e Pinus sp.), além de três espécies frutíferas e dois indivíduos de Eucalyptus sp. Com relação às invasoras, há necessidade de maior atenção por parte dos gestores públicos quanto à erradicação dessas espécies da área, visando à conservação das espécies nativas e recuperação do fragmento.

Essa questão se torna ainda mais preocupante quando se analisam os dados de densidade das espécies. Entre as espécies com maior número de indivíduos, duas são exóticas, L. lucidum $\left(261,04\right.$ ind ha $\left.{ }^{-1}=28,1 \%\right)$ e Diospyrus kaki $\left(112,45\right.$ ind $\left.\mathrm{ha}^{-1}=12,1 \%\right)$, sendo a primeira uma espécie com grande potencial invasor.

Há ainda, no fragmento urbano, grande presença de espécies nativas $(77,1 \%)$, representadas por apenas $46,3 \%$ dos indivíduos. Pode-se observar que há uma predominância de indivíduos de espécies exóticas em detrimento das nativas. Tal situação é verificada, também, na trilha do Poço Preto no Parque Nacional do Iguaçu, PR (Rodolfo et al., 2008), no Parque Barreirinha de Curitiba, PR (Mielke et al., 2015), em mata ciliar urbana em Dois Vizinhos, PR (Biz et al., 2015), entre outros.

A presença de espécies exóticas é comum em áreas com remanescentes florestais que sofrem influência do meio urbano, conforme afirma Fonseca et al. (2013), em estudo sobre a estrutura e diversidade da regeneração arbórea de uma floresta secundária urbana em Juiz de Fora, MG, onde observaram a predominância de indivíduos arbóreos da espécie exótica Syzygium jambos $(22,1 \%)$, competindo por espaço e nutrientes com as espécies nativas e prejudicando o desenvolvimento sucessional da área.

O predomínio de espécies exóticas invasoras influencia a diversidade biológica, bem como acarreta diversos impactos ambientais na área. $\mathrm{O}$ fragmento urbano analisado apresentou índice de diversidade de Shannon intermediário $\left(\mathrm{H}^{\prime}=2,88\right)$, muito semelhante a 
valores encontrados por Fonseca \& Carvalho (2012) em um fragmento de Mata Atlântica em área urbana de Juiz de Fora, $M G$, para uma área amostral de 1 ha $\left(\mathrm{H}^{\prime}=2,82\right)$.

No entanto, quando comparado com índices obtidos em áreas menos antropizadas, o valor de H' do presente trabalho é inferior. Bracht et al. (2011) obtiveram H' = 3,27 numa área localizada entre Floresta Ombrófila Mista e Estacional Semidecidual em Santa Catarina. Na região Sudoeste do Paraná, Estevan et al. (2011), estudando um fragmento florestal de Floresta Estacional Semidecidual, encontraram $H^{\prime}=3,71$, com diversidade superior ao fragmento do presente estudo e de outros realizados em áreas sob influência urbana.

Nem todo fragmento florestal urbano apresenta H' baixo ou intermediário. Em estudo realizado por Cielo Filho \& Santin (2002), em fragmento florestal urbano no bosque dos Alemães, em Campinas, SP, os autores estimaram $\mathrm{H}^{\prime}=3,45$, utilizando censo das espécies arbóreas com circunferência a 1,30 m do solo (DAP) a 15 $\mathrm{cm}$, mostrando que, conforme o estado de conservação, fragmentos florestais urbanos também podem apresentar diversidade compatível com fragmentos florestais em melhor estado de conservação.

No trabalho de Cielo Filho \& Santin (2002) também é discutido o alto valor de cobertura para espécies introduzidas e baixo para nativas regionais. Esse resultado é consistente com o observado no bosque do Lago da Paz. Um dos maiores problemas de conservação dos remanescentes florestais em áreas urbanas não se refere à baixa diversidade geral, aspecto que leva em conta também as espécies exóticas existentes, mas sim à alta densidade e dominância das espécies exóticas, muitas delas com característica invasora.

Apesar do elevado índice de Equabilidade de Pielou obtido na área $(>0,8)$, observa-se que, há uma dominância de poucas espécies, a maioria delas invasoras. Tal fato é normal para áreas com invasão de espécies exóticas, que se adaptam facilmente ao ambiente, dominando as nativas.

Entre as espécies observadas (Tabela 1), houve predominância dos grupos ecológicos clímax exigentes em luz e pioneiras, representando $86 \%$ das espécies, contra apenas $14 \%$ de espécies clímax tolerantes à sombra. Tal situação denota que o fragmento estudado se encontra em estágio de sucessão secundário, ambientes que geralmente são mais susceptíveis aos processos de invasão por espécies exóticas que apresentem tal potencial (Dislich et al., 2001).
De modo geral, mesmo com o raleio da vegetação de sub-bosque, há uma regeneração potencial para ser conduzida de modo a atingir o dossel, principalmente considerando as varas. Notou-se a presença das exóticas invasoras, ligustro e ameixeira-amarela, na área (Tabela 2) e ocorreu um exemplar da canela exótica (Cinnamomum zeylanicum), a qual, apesar de não ser considerada invasora, possivelmente está passando a regenerar em fragmentos florestais urbanos por estar sendo plantada na arborização de ruas da cidade há alguns anos. As demais espécies são nativas regionais, porém generalistas. Não há regeneração de araucária nem de outras espécies raras na região, como erva-mate, imbuia, peroba, pau-marfim, grápia, entre outras de interesse madeireiro e ecológico. Isso justifica que seja feito o plantio de enriquecimento.

Em bosques urbanos deve-se buscar o uso de espécies nativas ou exóticas sem potencial de invasão, uma vez que muitas espécies exóticas introduzidas em arborização de parques ou vias urbanas atualmente são encontradas até em unidades de conservação, após o início da ocorrência de um processo de dispersão, aspecto que é mostrado em diversos trabalhos que avaliam o problema, como por exemplo em Biz (2017). O controle de exóticas invasoras é geralmente difícil e dispendioso (Ziller et al., 2007). Duas das espécies encontradas no bosque tem alto potencial invasor em florestas nativas na região, H. dulcis e L. lucidum (Instituto Ambiental do Paraná, 2015). Em ambientes florestais, a maioria das espécies do gênero Pinus e Eucalyptus não tem potencial invasor elevado, assim como o caqui. As espécies de Citrus sp. apresentam médio poder invasor (Instituto Ambiental do Paraná, 2015).

Analisando-se as espécies nativas encontradas, notase que a área tem um significativo valor ecológico, pois foram registrados espécies como Araucaria angustifolia, presente na lista de espécies ameaçadas de extinção, e outras como Eugenia uniflora, de grande importância ecológico/econômica e grande distribuição, (Aguiar et al., 2013), Ilex microdonta, de significativa ocorrência em florestas nativas no Paraná (Miranda, 2015) e Cedrella fissilis, que é uma das espécies nativas madeireiras mais nobres do Brasil, de ampla ocorrência em todo o território nacional (Carvalho, 2005).

O controle de espécies exóticas invasoras, tanto em fragmentos florestais como também em parques, praças e na arborização de ruas de cidades, deve ser uma preocupação constante dos gestores, visando diminuir 
as perdas de biodiversidade nestes ecossistemas, geralmente com alto grau de antropização. Para tal, quanto mais cedo for detectado o problema, através de monitoramento periódico, mais rápidas e baratas serão as práticas silviculturais de controle, as quais podem ser mecânicas, químicas, biológicas ou ambientais (Instituto Horus, 2017). Os controles variam em sua aplicação, dependendo do caso, e devem ser monitorados de forma específica.

\section{Conclusão}

O fragmento florestal urbano estudado em Dois Vizinhos, PR encontra-se bastante alterado, tanto do ponto de vista florístico, como da sua estrutura fitossociológica, como consequência de ação antrópica.

Há grande presença de espécies exóticas, algumas potencialmente invasoras e outras frutíferas, comuns na região, introduzidas pela própria população para arborização urbana e para alimentação.

A regeneração natural é ainda mais susceptível aos impactos antrópicos na área, apresentando poucos indivíduos, sendo muitos de espécies exóticas invasoras.

Em florestas urbanas, onde se verifique a alta frequência e dominância de espécies exóticas invasoras no componente arbóreo e na regeneração, recomendamse intervenções silviculturais, visando à erradicação destas espécies e, com isso, a recuperação da estrutura original da floresta, com manejo da regeneração e o enriquecimento com espécies nativas.

\section{Agradecimentos}

Á Prefeitura Municipal de Dois Vizinhos, pela concessão de bolsa de extensão para o projeto "Revitalização das Praças de Dois Vizinhos" e à Associação de Proteção à Maternidade e Infância (APMI), pelo apoio logístico para a coleta de dados.

\section{Referências}

Aguiar, R.V. et al. Variabilidade genética de Eugenia uniflora L. em remanescentes florestais em diferentes estágios sucessionais. Revista Ceres, v. 60, n. 2, p. 226-233, 2013. DOI: 10.1590/S0034737 X2013000200011.

Alvares, C. A. et al. Köppen's climate classification map for Brazil. Meteorologische Zeitschrift, v. 22, n. 6, p. 711-728, 2013. DOI: 10.1127/0941-2948/2013/0507.
Badiru, A. I. et al. Método para a classificação tipológica da floresta urbana visando o planejamento e a gestão das cidades. In: SIMPÓSIO BRASILEIRO DE SENSORIAMENTO REMOTO, 12., 2005, Goiânia. Anais... Goiânia: INPE, 2005. p. 1427-1433.

Bianchini, E. et al. Diversidade e estrutura de espécies arbóreas em área alagável no município de Londrina, Sul do Brasil. Acta Botânica Brasílica, v. 17, n. 3, p. 405-419, 2003. DOI: 10.1590/ S0102-33062003000300008.

Biz, S. Dinâmica e sequestro de carbono em floresta ombrófila mista aluvial urbana. Dissertação. 2017. 107 f. Dissertação (Mestrado em Agronomia). Universidade Estadual do Centro-Oeste (Unicentro). Guarapuava.

Biz, S. et al. Levantamento florístico da mata ciliar urbana do córrego Água Turva em Dois Vizinhos-PR. Revista Brasileira de Arborização Urbana, v. 10, n. 2, p. 14-26, 2015.

Bracht, D. S. et al. Levantamento fitossociológico de um remanescente florestal no município de Xanxerê-SC. Unoesc \& Ciência, v. 2, n. 2, p. 165-174, 2011.

Carvalho, P. E. R. Cedro. Colombo: Embrapa Florestas. 2005. 17 p. (Embrapa Florestas. Circular técnica, 113).

Cielo Filho, R. \& Santin, D. A. Estudo florístico e fitossociológico de um fragmento florestal urbano - Bosque dos Alemães, Campinas, SP. Revista Brasileira de Botânica, v. 25, n. 3, p. 291-301, 2002. DOI: $10.1590 / \mathrm{S} 0100-84042002000300005$.

Constanza, R. et al. The value of the world's ecosystem services and natural capital. Nature, v. 387, p. 253-260, 1997. DOI: $10.1038 / 387253 \mathrm{a} 0$.

Dislich, R. et al. Análise da estrutura de fragmentos florestais no Planalto Paulistano - SP. Revista Brasileira de Botânica, v. 24, n. 3, p. 321-332, 2001. DOI: 10.1590/S1676-06032009000200018.

Estevan, D. A. et al. Estrutura e diversidade arbórea em fragmento florestal no salto do Rio Chopim, São Jorge D'Oeste-Paraná, Brasil. In: CONGRESSO DE CIÊNCIA E TECNOLOGIA DA UTFPR CÂMPUS DOIS VIZINHOS, 1., 2011, Dois Vizinhos. Anais... Dois Vizinhos: UTFPR, 2011.

Felfili, J. M. et al. Fitossociologia no Brasil: métodos e estudos de caso: volume I. Viçosa, MG: Ed da UFV; Sociedade Botânica do Brasil, 2011. 558 p.

Fonseca, C. R. \& Carvalho, F. A. Aspectos florísticos e fitossoociológicos da comunidade arbórea de um fragmento urbano de floresta Atlântica (Juiz de Fora, MG, Brasil). Bioscience Journal, v. 28, n. 5, p. 820-832, 2012.

Fonseca, S. N. et al. Estrutura e diversidade da regeneração arbórea em uma floresta secundária urbana (Juiz de Fora, MG, Brasil). Floresta e Ambiente, v. 20, n. 3, p. 307-315, 2013. DOI: 10.4322/ floram.2013.031.

Hirota, M. (Coord.). Atlas dos remanescentes florestais da Mata Atlântica: período de 2008- 2010. São Paulo: Fundação SOS Mata Atlântica: Instituto Nacional de Pesquisas Espaciais, 2011.

Iniciativa Verde. Programas e Projetos. 2017. Disponível em: $<$ http://www.iniciativaverde.org.br/programas-e-projetos-programanascentes.php $>$. Acesso em: 19 dez. 2017. 
Instituto Ambiental do Paraná. Portaria IAP n⿳0 059, de 15 abril de 2015. Reconhece a Lista Oficial de Espécies Exóticas Invasoras para o Estado do Paraná, estabelece normas de controle e dá outras providências. Disponível em: <http://www.iap.pr.gov.br/arquivos/ File/Lista_invasoras_PR_corrigida_set_2015.pdf $>$. Acesso em: 22 jan. 2017.

Instituto Hórus de Desenvolvimento e Conservação Ambiental. Métodos de controle de espécies exóticas invasoras. Disponível em: <http://www.institutohorus.org.br/pr_metodos_controle.htm $>$. Acesso em: 18 dez. 2017.

Kersten, R. de A. et al. Floresta Ombrófila Mista: aspectos fitogeográficos, ecológicos e métodos de estudo. In: Eisenlohr, P. V. et al. (Ed.). Fitossociologia no Brasil: métodos e estudos de casos: volume II. Viçosa, MG: Ed da UFV, 2015. p. 156-182.

Klein, R. M. Árvores nativas da floresta subtropical do Alto Uruguai. Sellowia, v. 24, n. 24, p. 9-62, 1972.

Konijnendijka, C. C. et al. Definição de silvicultura urbana - Uma perspectiva comparativa da América do Norte e Europa. Urban Forestry \& Urban Greening, v. 4, p. 93-103, 2006.

Magurran, A. E. Medindo a diversidade biológica. Curitiba: UFPR, 2013. $261 \mathrm{p}$.

McKinney, M. L. Effects of urbanization on species richness: A review of plants and animals. Urban Ecosystems, v. 11, n. 2, p. 161-176, 2008. DOI: 10.1007/s11252-007-0045-4.

Mielke, E. C. et al. Espécies exóticas invasoras arbóreas no Parque da Barreirinha em Curitiba: registro e aplicações. Ciência Florestal, v. 25 , n. 2, p. 327-336, 2015. DOI: 10.5902/1980509818451.

Miranda, B. P. Dendroecologia de Ilex microdonta Reissek e Drimys brasiliensis Miers em dois ambientes altomontanos da Serra do Mar, Paraná, Brasil. 2015. 95 f. Dissertação (Mestrado em Engenharia Florestal) - Universidade Federal do Paraná. Curitiba. 2015.

Mueller-Dombois, D. \& Ellenberg, H. Aims and methods of vegetation ecology. New York: Blackburn Press, 2002. 547 p.

Nowak, D. J. et al. Assessing urban forest effects and Values, New York City's urban forest. Newtown Square: USDA, Forest Service, Northern Research Station, 2007. 22 p. (USDA. Resource Bulletin. NRS-9)

Reitz, R. et al. Projeto madeira do Rio Grande do Sul. Porto Alegre: CORAG, 1988. 525 p.
Rezende, T. M. \& Santos, D. G. Avaliação quali-quantitativa da arborização das praças do bairro Jaraguá, Uberlândia - MG. Revista Brasileira de Arborização Urbana, v. 5, n. 2, p. 139-157, 2010.

Rodolfo, A. M. et al. Citrus aurantium L. (laranja-apepu) e Hovenia dulcis Thunb. (uva-do-japão): espécies exóticas invasoras da trilha do Poço Preto no Parque Nacional do Iguaçu, Paraná, Brasil. Revista Brasileira de Biociências, v. 6, n. 1, p. 16-18, 2008.

Salbitano, F. et al. Guidelines on urban and peri-urban forestry. 2016. Rome: FAO, 2016. (FAO. Forestry Paper, 178). Disponível em: < http://www.fao.org/3/a-i6210e.pdf > . Acesso em: 20 jan. 2017.

Salles, J. C. \& Schiavini, I. Estrutura e composição do estrato de regeneração em um fragmento florestal urbano: implicações para a dinâmica e a conservação da comunidade arbórea. Acta Botânica Brasílica, v. 21, n. 1, p. 223-233, 2007. DOI: 10.1590/S010233062007000100021.

Santos, H. G. dos. et al. Sistema brasileiro de classificação de solos. 3. ed. Brasília, DF: Embrapa, 2013. 353 p.

Schorn, L. A. et al. Fitossociologia de fragmentos de Floresta Estacional Decidual no estado de Santa Catarina - Brasil. Ciência Florestal, v. 24, n. 4, p. 821-831, 2014. DOI: 10.5902/1980509816582.

Scipione, M. C. et al. Composição florística e estratégias de dispersão e regeneração de grupos florísticos em florestas estacionais deciduais no Rio Grande do Sul. Floresta, v. 43, n. 2, p. 241-254, 2013. DOI: 10.5380/rf.v43i2.27098.

Silva, R. K. S. et al. Florística e sucessão ecológica da vegetação arbórea em área de nascente de um fragmento de Mata Atlântica, Pernambuco. Revista Brasileira de Ciências Agrárias, v. 5, n. 4, p. 550-559, 2010. DOI: 10.5039/agraria.v5i4a829.

Swaine, A. \& Whitmore, T. C. On the definition of ecological species groups in tropical rain forests. Vegetatio, v. 75, p. 81-86, 1988.

Tabarelli, M. Flora arbórea da Floresta Estacional Baixo-Montana no município de Santa Maria, RS, Brasil. Revista do Instituto Florestal, São Paulo, v. 4, pt. 1, p. 260-268, 1992. Edição dos Anais do Congresso Florestal de Essências Nativas, 2., 1992, São Paulo. Edição especial.

Ziller, S.R. et al. Modelo para o desenvolvimento de uma estratégia nacional para espécies exóticas invasoras. Curitiba: TNC/GISP, 2007. 62 p. 